\title{
Excision and cauterization of pterygium-a case series study
}

\author{
Amer Y. Rajab \\ Department of Surgery. College of Medicine, University of Mosul.
}

(Ann. Coll. Med. Mosul 2008; 34(2): 126-128).

Received: $2^{\text {nd }}$ Oct 2007; Accepted: $23^{\text {nd }}$ July 2008.

\begin{abstract}
Aim: To review the different methods for treatment of pterygium.

Methods: A case series study conducted at private and out patients clinic of Al Jamhoury teaching hospital in Mosul, during the period from Jan.2006-Jun.2007. Thirty-eight patients with 54 eye lesions of pterygium were included in the study. They were treated under local anesthesia by simple surgical excision with cauterization of the conjunctival edges to sclera by simple cautery or by wet bipolar cautery.
\end{abstract}

Results: seven cases of recurrence were recorded in this study after 4-12 months of follow up postoperatively, in the age group before 45 years. No significant preoperative or postoperative complications were recorded with the exception of persistence of some cauterization marks on the sclera,

Conclusion: The surgical excision of pterygium and cauterization of the conjunctival edges to the sclera appear to be a simple, safe and successful method.

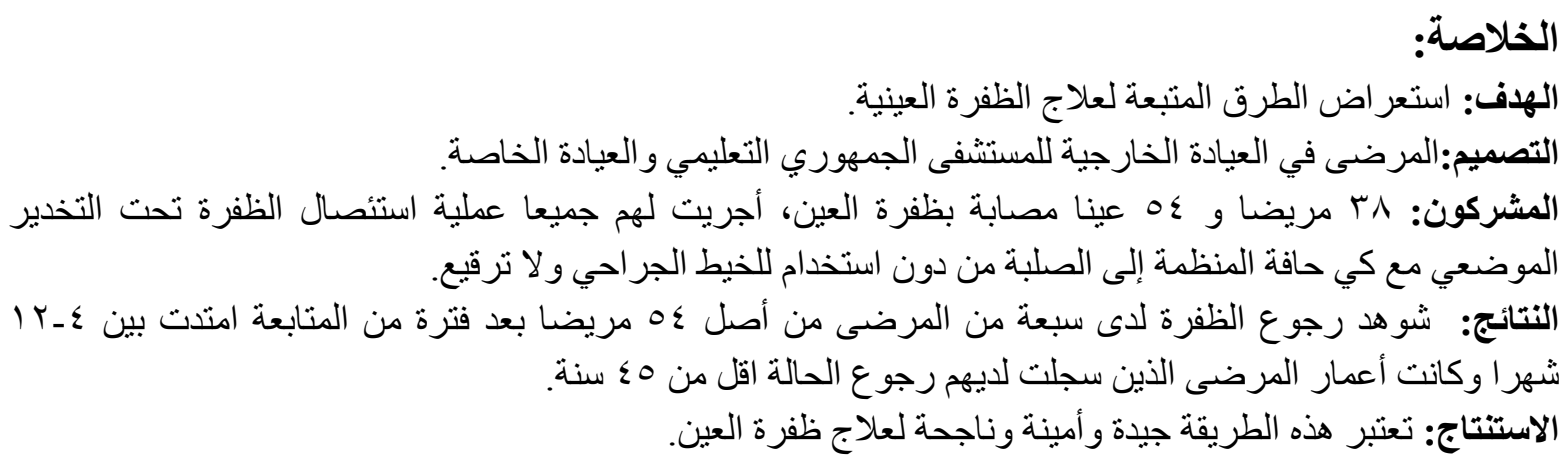

$\mathrm{P}$ terygium is a fibromuscular overgrowth of degenerative bulbar conjunctival tissue growing over the limbus on to the cornea ${ }^{(1)}$. It is world wide disease that causes chronic irritation, impaired cosmoses and decreased vision secondary to growth over the papillary axis or induced a stigmatism or disruption of the per corneal tear film ${ }^{(2)}$. Primary pterygium is believed to be a consequence of ultraviolet induced damage with subsequent elastoid degeneration of the sub-epithelial connective tissue ${ }^{(3)}$. The common problem facing surgical treatment is the recurrence. Many trials were done in order to decrease as much as possible the incidence of the recurrence such as the use of beta- irritation and mitomycin, but these modifications were found to be associated with higher incidence of complications ${ }^{(4)}$. The indications for surgical treatment include progression of the pterygium, interference with vision, limiting of ocular motility or cosmetic disfigurement ${ }^{(5)}$.

There are many techniques available for pterygium removal. They vary from simple 
excision to excision and repair of the defect with preserved material ${ }^{(6)}$. The most difficult problem faced in the management is its frequent and aggressive recurrence following surgical removal ${ }^{(7)}$. In spite of the many modalities and surgical techniques that have been developed for the treatment of recurrence it is still present as a surgical problem, due to symblepharon, fornix shortening and liability of corneal perforation $^{(8)}$.

The most accepted methods now for prevention of pterygium recurrence are application of anti metabolites, conjunctival or limbal auto grafts and amniotic membrane transplantation ${ }^{(8)}$. The aim of the study is to evaluate the outcome of this simple surgical excision of the primary pterygium.

\section{Patients and methods:}

Fifty-four eyes of 38 patients having primary pterygium were included in this study. Sixteen were males and 22 females with a mean age of 43.4years (range from 16-65 years). The mean follow up period was 12 months. We excluded from our study the recurrence cases for better evaluation of this technique, as it is well known that the recurrent cases have a worse prognosis than primary cases. So choosing the non-recurrence cases will give us better evaluation of the recurrence rate. In addition, we excluded from our study cases of pterygium associated with ocular surface diseases that might be contraindications to ocular surgery and may influence the incidence of recurrence as cases with dry eye syndrome or symblepharon.

Before surgery the best corrected Snellen visual acuity, intra ocular pressure by (Goldman applination tonometry) and detailed slit lamp and fundus examination were recorded. All the patients were operated on by the author under local peri-bulbar anesthesia, by simple surgical excision of the pterygium with $4.5-5 \mathrm{~mm}$, bare area and cauterization of the conjunctival edge to sclera instead of stitches.

\section{Results:}

There are 54 eyes of 38 patients operated on; 16 males and 22 were females with mean age of 43.4 years ranged from 16-65. the mean follow up period was 12 months; all our patients had primary pterygium at the nasal side.

Seven cases of recurrence were noted within the study period, two occurring at 4 month, and 3 occurring 4.5 months and two occurring 5.5 months post operatively.

These cases of recurrence were seen in the age group of before 45 years or younger, while no recurrence was recorded above 45 years. No significant intra-operative or postoperative complications were recordered with the exception of the cauterization marks in all our cases that resolved within 2-4 months postoperatively. There was no statistical significant difference between the pre operative and post-operative mean best corrected visual activity which was 6/12: range $(6 / 24-6 / 6)$. Also there was no statistically significant difference between preoperative and post-operative mean intraocular pressure: $18.0 \mathrm{mmHg}$, ranged from (11-21).

No complications were recorded from periocular anesthesia in our cases.

\section{Discussion:}

Pterygium is a worldwide degenerative corneal disease with a diverse etiology. It is particularly common in tropical and sub tropical countries. Although different treatment regimes have been proposed for its treatment, the main complication of pterygium treatment is the recurrence of the disease $e^{(9)}$. Various techniques were made to decrease the incidence of recurrence such as radiotherapy, anti metabolites, conjunctival or limbal autograft transplantation ${ }^{(3)}$.

In a study done by Multu et $\mathrm{al}^{(1)}$, the recurrence rate of pterygium excision and limbal conjunctival autograft transplantation was $14.6 \%$ while the recurrence rate in cases of use of intra operative Mitomycin C $(0.2 \mathrm{mg} / \mathrm{ml})$ combined with conjunctival flap closure was $12.5 \%$. All cases of recurrence were seen by the end of the first post operative year, with the average time for limbal conjunctival autograft transplantation of $4.8 \pm 1.9$ and the use of intra operative mitomycin $4.2 \pm 1.7$ months ${ }^{(10)}$. The results in 
our study are nearly similar. We met seven cases of recurrence in the 12 months followup with an incidence of $12.8 \%$, with the recurrence occurring between the second and sixth months post operatively.

Younger age patients are known to be associated with increased rate of pterygium recurrence ${ }^{(11,12)}$. In Multu et al study, the mean age of recurrence in limbal conjunctival auto graft transplantation was $25.8 \pm 8.5$ years and in patients with the use of intra-operative mitomycin was $27.2 \pm 8.2$ years.

In our study, the cases of recurrence were seen in seven cases with the age less than 45 years. The study shows the safety and efficacy of our methods, which is comparable to recurrence rate on studies of conjunctival grafts, which ranges from $2 \%-39 \%{ }^{(2)}$. In 1989 , Kenyon and Tseng showed the limbus to be a distinct structure lying between the corneal and conjunctival epithelium containing stem cells that are vital for normal corneal epithelium regeneration and preventing the growth of conjunctival epithelium on to the cornea through contact inhibition. It has been proposed that pterygium arises as a result of a local limbal ultraviolet-related damage to inter palpebral limbal stem cells ${ }^{(13)}$.

For these reason in my work no toxic drugs were used avoiding their injurious effect on normal stem cells that are vital for normal corneal epithelial regeneration and for preventing the growth of conjunctival epithelium on the cornea with recurrence of the pterygium.

\section{Conclusion:}

The surgical excision of the pterygium with $4.5-5 \mathrm{~mm}$ bare area and cauterization of the conjunctival edge to sclera appears to be simple, safe and successful method.

\section{References:}

1. Mutlu FM, Sobaci G, Tatar T, Yildirim E: A comparative study of recurrent pterygium surgery. Ophthalmology 1999; 106:817-821.

2. Chen PP, Ariyasu RG, Kaza V: A randomized trial comparing mitomycin $\mathrm{C}$ and conjunctival autograft after excision of primary pterygium Am J Ophthalmology. 1995;120:151-160

3. Jaros PA, De luise VP: Pingecula and pterygium. Surgery. Ophthalmology. 1988; 33:41-49.

4. Krag S, Ehlers N: Excimer laser treatment of pterygium Acta Ophthalmol (Copenh) 1992; 70:530-533.

5. Taha HN, Hamed AH, Khallaf M Youssef A, Conjunctival autograft transplantation in pterygium surgery .Bull. Ophthalmology. Soc. Egypt 1999; 92:1131-1134.

6. Figueiredo RS, Cohen EJ Gomes JA Rapauno CJ and laipson PR, Conjunctival autograft for pterygium surgery: How will do it Prevent Recurrence? Ophthalmic surgery lasers 1997; 28:99-104.

7. Manning CA, Kloess PM, Diaz D, and Yee RW Intra-operative Mitomycin in primary pterygia excision .Ophthalmology 1997; 104:844-848.

8. Ma DH,See LC, liau SB et al: Amniotic membrane graft for primary pterygium comparison with conjunctival autograft and topical mitomycin $\mathrm{C}$ treatment . $\mathrm{Br} \mathrm{J}$ ophthalmology 2000; 84(4):973 - 8.

9. Mahar PS Nwokora GE: Role of mitomycin C in pterygium surgery. $\mathrm{Br} \mathrm{J}$ Ophthalmology .1993: 17:433-435.

10. Mastropasque L, Carpiento $P$, Ciancaglini M, Gallenga PE: long term result of intraoperative mitomycin $\mathrm{C}$ in the treatment of recurrent pterygium. $\mathrm{Br}$. ophthalmology .1996; 80:288-291.

11. Lewallen S: A randomized trial of conjunctival autograft for pterygium in the tropics. Ophthalmology 1989;96:1612-1614

12. Strack T Kenyon KR Serrano F: Conjunctival autograft for primary and recurrent pterygia surgical technique and problem management Cornea Br. J. ophthalmology 1991; 10:196202.

13.Kenyon KR, Tseng SCG: limbal autograft transplantation for ocular surface disorders. Ophthalmology 96:709-723, 1989.

14.Tseng SCG: Concept and application of limbal stem cells. Eye 1989; 3:141-157. 